\title{
Pelaksanaan Penyuluhan tentang Gangguan Menstruasi dan Pembagian Buku Saku pada Wanita Usia Subur di Desa Penyengat Olak Kec. Jambi Luar Kota Kab. Muaro Jambi Tahun 2019
}

\author{
Enny Susilawati ${ }^{1}$, Lia Artika Sari ${ }^{2}$ \\ ${ }^{1,2}$ Jurusan Kebidanan, Poltekkes Kemenkes Jambi \\ Email : ennykahfi80@gmail.com
}

Submitted : 08/06/2021

Accepted: 14/06/2021

Published: 28/06/2021

\begin{abstract}
Women of reproductive age have many problems or abnormal menstruation, such as menstrual syndrome and irregular menstruation (Johnson, 2004). Women of reproductive age in modern times are often faced with various psychosocial, medical and economic problems, which can cause stress for women who are unable to adapt to external and internal pressures. So stress can be said as an etiologic factor of menstrual disorders. (Kaplan and Manuck, 2004; Wang et al., 2004). Stress is a physiological, psychological response of humans trying to adapt and regulate both internal and external pressures. This community service activity aims to make women of childbearing age aware of the importance of knowing about types of menstrual disorders and how to overcome them. The activities carried out from April 2019, the activities carried out were: implementation of menstrual disorders and the distribution of pocket books to women of childbearing age (WUS) in Penyengat Olak Village, Kec. Jambi Outer City District. Muaro Jambi Year 2019. So that the Puskesmas officers continue to improve counseling, especially about various types of menstrual disorders and how to overcome them.
\end{abstract}

Keywords: menstrual disorders, women of childbearing age

\begin{abstract}
Abstrak
Wanita usia reproduktif banyak memiliki masalah menstruasi atau haid yang abnormal,seperti sindrom menstruasi dan menstruasi yang tidak teratur (Johnson,2004). Wanita-wanita usia reproduktif zaman modern seperti sekarang ini sering dihadapkan pada berbagai masalah-masalah psikososial, medis dan ekonomi, sehingga dapat menimbulkan stres bagi wanita yang tidak mampu beradaptasi dengan tekanan eksternal dan internal. Sehingga stres dapat dikatakan sebagai faktor etiologi dari gangguan menstruasi.(Kaplan and Manuck, 2004; Wang dkk, 2004).Stres merupakan suatu respon fisiologis, psikologis manusia yang mencoba untuk mengadaptasi dan mengatur baik tekanan internal dan eksternal. Kegiatan Pengabdian masyarakat ini bertujuan agar wanita usia subur dapat mengetahui pentingnya untuk mengetahui tentang macam macam gangguan menstruasi dan cara mengatasinya. Kegiatan dilaksanakan dari pada bulan April 2019, kegiatan yang dilakukan berupa, pelaksanaan penyuluhan tentang gangguan menstruasi dan pembagian buku saku pada wanita usia subur(WUS) di Desa Penyengat Olak Kec. Jambi Luar Kota Kab. Muaro Jambi Tahun 2019 pelaksanaan penyuluhan tentang gangguan menstruasi dan pembagian buku saku pada wanita usia subur(WUS) di Desa Penyengat Olak Kec. Jambi Luar Kota Kab. Muaro Jambi Tahun 2019 Agar petugas Puskesmas terus meningkatkan kegiatan penyuluhan terutama tentang macam-macam gangguan menstruasi dan cara mengatasinya.
\end{abstract}

Kata Kunci: gangguan menstruasi, wanita usia subur

\section{PENDAHULUAN}

Saat ini penyuluhan kesehatan Ibu dan Anak pada umumnya masih banyak dilakukan melalui konsultasi perorangan atau kasus per kasus yang diberikan pada waktu pasien datang berobat. Kegiatan penyuluhan semacam ini bermanfaat untuk menangani kasus per kasus namun memiliki kelemahan antara lain: pengetahuan yang diperoleh hanya terbatas pada masalah kesehatan yang dialami saat konsultasi, penyuluhan yang diberikan tidak 
terkoordinir sehingga ilmu yang diberikan kepada ibu hanyalah pengetahuan yang dimiliki oleh petugas saja, tidak ada rencana kerja sehingga tidak ada pemantauan atau pembinaan secara lintas sektor dan lintas program, pelaksanaan penyuluhan tidak terjadwal dan tidak berkesinambungan.

Menstruasi adalah proses keluarnya darah dari vagina yang terjadi diakibatkan siklus bulanan alami pada tubuh wanita. Siklus ini merupakan proses organ reproduksi wanita untuk bersiap jika terjadi kehamilan. Persiapan ini ditandai dengan penebalan dinding rahim (endometrium) yang berisi pembuluh darah. Jika tidak terjadi kehamilan, endometrium akan mengalami peluruhan dan keluar bersama darah melalui vagina.

Siklus haid yang terjadi diluar keadaan normal, atau dengan kata lain tidak berada pada interval pola haid pada rentang waktu kurang dari 21 atau lebih dari 35 hari dengan interval pendarahan uterus normal kurang dari 3 atau lebih dari7 hari disebut siklus menstruasi/haid yang tidak teratur (Berek, 2002).

Gangguan Haid digolongkan atas 4 bagian yaitu kelainan banyaknya darah dan lamanya pendarahan pada haid, kelainan siklus, perdarahan di luar haid, gangguan haid yang ada hubungannya dengan haid (Wiknjosastro, 2008). Menurut Berek (2002) ada enam jenis gangguan menstruasi yang termasuk kedalam siklus menstruasi yang tidak teratur adalah oligomenorea, polimenorea, menoragia, metroragia, menometroragia, hipomenorea. Perubahan pola haid dipengaruhi usia seseorang (Wiknjosastro, 2008), pemakaian kontrasepsi (Llewellyn, 2005), penyakit pada ovarium misalnya: 2 tumor, kelainan pada sistem saraf pusat- Hipotalamus dan Hipofisis (Benson, Ralph C. dan Pernoll, Martin L., 2009).

Perubahan pola haid normalnya terjadi pada kedua ujung siklus haid, yaitu waktu remaja dan menjelang menoupause. Dalam siklus haid masa remaja dan menjelang menoupase, dinding rahimnya hanya dirangsang pertumbuhannya oleh estrogen.Hanya hormon FSH saja yang dikeluarkan oleh kelenjar bawah otak.Akibatnya siklus haid tidak teratur (Llewellyn, 2005).

Wanita usia reproduktif banyak memiliki masalah menstruasi atau haid yang abnormal, seperti sindrom menstruasi dan menstruasi yang tidak teratur (Johnson, 2004). Wanita-wanita usia reproduktif zaman modern seperti sekarang ini sering dihadapkan pada berbagai masalah-masalah psikososial, medis dan ekonomi, sehingga dapat menimbulkan stres bagi wanita yang tidak mampu beradaptasi dengan tekanan eksternal dan internal. Sehingga stres dapat dikatakan sebagai faktor etiologi dari gangguan menstruasi. (Kaplan and Manuck, 2004; Wang dkk, 2004).Stres merupakan suatu respon fisiologis, psikologis manusia yang mencoba untuk mengadaptasi dan mengatur baik tekanan internal dan eksternal (Pinel, 2009).

\section{TARGET DAN LUARAN}

Khalayak sasaran dalam pengabdian masyarakat ini adalah wanita usia subur yang di Desa Penyengat Olak Kec. Jambi Luar Kota Kab. Muaro Jambi Tahun 2019. Jumlah mitra ini ditetapkan dengan mempertimbangkan efisiensi dan intensitas pelaksanaan program. Mitra yang merupakan perempuan yang dalam masa usia subur yang berasal dari Desa Penyengat Olak Kecamatan Jambi Luar Kota Kabupaten Muaro Jambi, jenis permasalahan yang ditangani dalam kegiatan ini adalah dengan cara memberikan penyuluhan dan pembagian buku saku tentang gangguan menstruasi dan cara mengatasinya.

Luaran dari kegiatan ini adalah dapat menambah pengetahuan wanita usia subur tentang gangguan menstruasi dan cara mengatasinya.dapat menambah pengetahuan wanita usia subur tentang 
gangguan menstruasi dan cara mengatasinya.

cara memberikan penyuluhan dan pembagian buku saku tentang gangguan menstruasi dan cara mengatasin

\section{METODE PELAKSANAAN}

Pengabdian ini dilakukan dengan cara memberikan penyuluhan dan pembagian buku saku tentang gangguan menstruasi dan cara mengatasinya. Kegiatan dilakukan di desa Penyengat Olak Kec. Jambi Luar Kota Kab. Muaro Jambi Tahun 2019, peserta yang hadir di acara penyuluhan adalah wanita usia subur di desa Suka Maju Kec Mestong Kab Muaro Jambi sebanyak 40 orang. Pelaksanaan kegiatan dilakukan di bulan April 2019.

Kegiatan penyuluhan tentang gangguan menstruasi dan pembagian buku saku pada wanita usia subur (WUS) dapat tercapai dan terlaksana pada saat wanita usia subur datang ke Posyandu di Desa Penyengat Olak Kec. Jambi Luar Kota Kab. Muaro Jambi Tahun 2019dilakukan di desa Penyengat Olak Kec. Jambi Luar Kota Kab. Muaro Jambi Tahun 2019, peserta yang hadir di acara penyuluhan adalah wanita usia subur di desa Suka Maju Kec Mestong Kab Muaro Jambi sebanyak 40 orang. Pelaksanaan kegiatan dilakukan di bulan April 2019di desa Penyengat Olak Kec. Jambi Luar Kota Kab. Muaro Jambi Tahun 2019, peserta yang hadir di acara penyuluhan adalah wanita usia subur di desa Suka Maju Kec Mestong Kab Muaro Jambi sebanyak 40 orang. Pelaksanaan kegiatan dilakukan di bulan April 2019.

Kegiatan penyuluhan tentang gangguan menstruasi dan pembagian buku saku pada wanita usia subur dapat tercapai dan terlaksana pada saat wanita usia subur datang ke Posyandu..

\section{HASIL DAN PEMBAHASAN}

Pelaksanaan kegiatan pengabdian masyarakat dilaksanakan di rumah Kader di Desa Suka Maju Kecamatan Mestong
Kabupaten Muaro Jambi. Kegiatan ini dilaksanakan pada bulan April 2019.

Hasil dari beberapa tahapan pelaksanaan pada kegiatan pengabdian masyarakat yaitu tahap perencanaan sudah dilakukan pertemuan dan kerjasama dengan pihak Pak Lurah, Bidan, Kader, serta kepala Desa untuk pelaksanaan penyuluhan dan pembagian buku saku tentang gangguan menstruasi dan cara mengatasinya.

Hal ini sesuai dengan yang dikemukakan oleh Green (2005) bahwa perilaku seseorang di pengaruhi oleh beberapa faktor salah satunya adalah faktor predisposisi yaitu pengetahuan. Pengetahuan merupakan faktor yang mempermudah atau mempredisposisikan terjadinya perilaku sesorang. Pengetahuan seseorang akan suatu program kesehatan akan mendorong orang tersebut mau berpartisipasi didalamnya. Pada dasarnya, pengetahuan merupakan domain yang sangat penting untuk terbentuknya tindakan seseorang. Perilaku yang didasari dengan pengetahuan akan lebih baik daripada perilaku yang tidak didasari dengan pengetahuan. Salah satu faktor yang mempengaruhi perilaku seseorang adalah pengetahuan. Namun, pembentukan perilaku itu sendiri tidak semata-mata berdasarkan pengetahuan, tetapi masih dipengaruhi oleh banyak faktor yang sangat kompleks.

Hasil evaluasi yang dilakukan setelah diberikan penyuluhan ibu dapat menjelaskan kembali tentang macammacam gangguan menstruasi dan cara mengatsinya, pada akhir sesi pertemuan ibu diberikan buku saku dengan harapan WUS dapat membaca kembali tentang materi yang sudah diberikan dalam penyuluhan. 


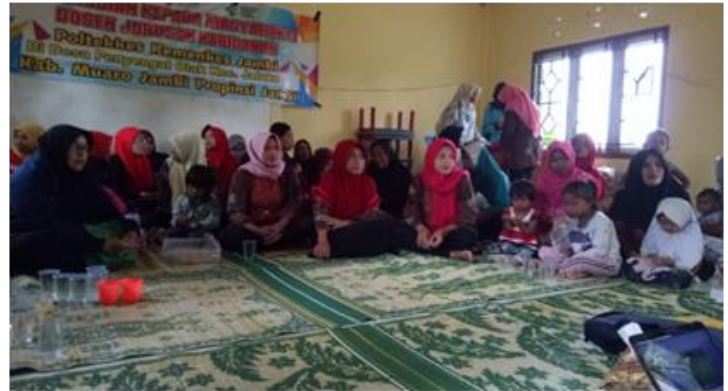

Gambar 1. Proses penyuluhan pada WUS

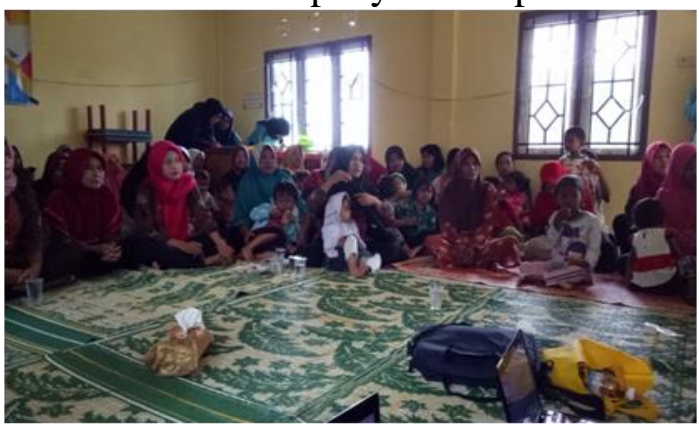

Gambar 2. Proses Tanya jawab dan pembagian buku saku

\section{KESIMPULAN DAN SARAN}

\section{Kesimpulan}

Kegiatan pengabdian masyarakat ini dapat disimpulkan bahwa tingkat ketercapaian sudah tercapai dengan baik, penyelesaian masalah menggunakan metode penyuluhan sudah mengatasi masalah ketidaktahuan WUS tenmtang macam-macam gangguan menstruasi dan cara mengatasinya

\section{Saran}

Agar petugas Puskesmas terus meningkatkan kegiatan penyuluhan terutama tentang macam-macam gangguan menstruasi dan cara mengatasinya.
Terima kasih tim ucapkan kepada seluruh pihak yang telah membantu kegiatan ini terlaksana terutama direktur.

\section{DAFTAR PUSTAKA}

Berek, J.S, 2002. Reproductive Physiologi.In Berek \& Novak's Ginecology. 13 th California: Lippincot William \& Wilkins, 71-79.

Kumalasari I, 2012 Kesehatan Reproduksi. Jakarta:

Kusmiran, Eni. 2010. Kesehatan Reproduksi Remaja dan wanita, Salemba Medika.

Manuaba, 2010. Memahami Kesehatan Reproduksi Wanita, EGC. Jakarta

Prawirohardjo, Sarwono, 2010. Ilmu Kebidanan. EGC. Jakarta

Llewellyn, Derek, Jones, 2005. Setiap Wanita: Buku Panduan Lengkap Tentang Kesehatan, Kebidanan dan Kandungan. Jakarta: Delataprasa. Hal 29-39

Benson, Ralph C., Pernoll, Martin L. 2009. Buku Saku Obstetri Ginecologi. Jakarta: EGC. Hal 630-631

Johnson, S.R., 2004. Premenstrual Syndrome, Premenstrual Dysphoric Disorder, and Beyond: A Clinical Primer For Practitioners. Obstet Gynecol. 104: 845-859.

Kaplan, J.R., Manuck, S.B., 2004. Ovarian Dysfunction, $\quad$ Stress, disease: $\quad A$ Primate Continuum. ILAR J. 45: 89115.

Pinel, J. P. J. 2009. Biopsikologi.Ed. 7. Yogyakarta: Pustaka Belajar. Hal 557565

\section{UCAPAN TERIMAKASIH}

